\title{
Ewa Ogrodzka-Mazur, Anna Szafrańska, Josef Malach and Milan Chmura: The cultural identity and education of university students in selected East-Central countries. A Polish-Czech comparative study. Göttingen 2021, Vandenhoeck \& Ruprecht Varlage, pp. 239 ISBN: 978-3-8471-1254-9. EISBN: 978-3-7370-1254-6. DOI: $10.14220 / 9783737012546$
}

\section{Originality of research questions and hypotheses}

This monograph asks several comparative questions about important characteristics of Polish and Czech university students, using theoretical frameworks drawn from international literature on intercultural education. The authors' deep knowledge of the institutional and cultural contexts of this research situation is always front and center, and provides a window into a fascinating borderland region that most readers from outside the region would like to know little about. In this sense, the research is already highly original and interesting. The research questions, taken at a more general level, are also interesting and relevant. This is partly achieved through an impressive mastery of the literature pertaining to intercultural and multicultural education, at the university level, and specifically through their attention to the theories of borderland identity development. Their research hypotheses are appropriately modest - not promising to explain everything - but sufficiently broad to be of great interest, and all 'testable'.

The notion of the borderland for scholars from other places is likely to be highly influenced by historical and geographical particularities of, for example, the American border, or postcolonial formations in Western Europe. Because scholars from the U.S.A and Western Europe have established intellectual hegemony in this discourse, one might come to believe that their borderlands are the only important ones, and that theories that explain how 
they work have universal application. As cultural insiders, from both sides of the national, linguistic, and cultural border in question, the authors here are able to dispel the illusion, drawing attention to other borderlands, from which we all can learn. They do this without ignoring the more general theories, thus providing an important addition to the theoretical and scientific literature about cultural border crossings, generally.

\section{Quality of methodology}

The authors employ a wide variety of methodological approaches - from ethnographic observations and interviews, to questionnaire and self-report - to address their research questions. The research purpose of each methodology, and its theoretical justifications, are laid out clearly in the methodological section. Their analyses demonstrate complete mastery of both qualitative and quantitative methodologies.

\section{Correctness of formulated conclusions}

The authors offer well-reasoned, evidence-based conclusions at the end of each chapter of the monograph. I admire the clarity of the presentation of the hypotheses, and the justifications for believing that a result is meaningful or not. There is sensitivity to the gray area between statistical significance and relevant tendencies evinced by the data, especially in the kind of muddy area of student evaluations of the institutions they attend, which are also in effect self-evaluations of the students' themselves. The chapters are mostly structured in such a way as to emphasize the results, with less space given to a discussion of the results. As a reader more inclined toward theory than data, I would have enjoyed somewhat more discussion and explanation of the statistical results, but that is probably a matter of personal preference. Though I think that the probable audience of this monograph - scholars and practitioners in higher education - would, like me, want to know a little more about what the authors believe the results mean, in light of the overall theoretical framework. For instance, in many cases, Czech students seemed to evaluate their educational experiences more highly than Polish students. I know that the data per se might not answer the question of why, but I wondered what the authors though might be the answer. 


\section{Presentation and style (English language)}

The presentation is clear and comprehensible, offered in correct English. The prose is appropriately formal, in an academic sense, but always accessible to a general readership, neither overly technical or obscure. There are sentences that I, as a native English speaker/writer, would have written differently (and perhaps better!) but the quality of the translation is more than adequate.

\section{Recommendation}

I would strongly recommend the publication of this monograph. There is intense interest in the field of higher education in the kinds of questions raised here, related to intercultural processes at all levels, the value of studying abroad, and student perceptions of the value of a university education. Many of these publications are very general, and do not offer the level of specificity with respect to some of the key questions, such as are offered here. I expect that this volume would be a valuable addition to university libraries and useful also for scholars and policy-makers. Parts of it would be useful also for teaching, and it is accessible to university students, even at an undergraduate level. 